\title{
GESTIÓN DE MUROS: EL GRAFFITI COMO CONFLICTO Y RECURSO
}

\section{WALL MANAGEMENT: GRAFFITI AS CONFLICT AND RESOURCE}

\section{LEDESMA, Ezequie}

Alumno becario de Pregrado SGCYT, Universidad Nacional del Nordeste. Facultad de Arquitectura y Urbanismo. Resistencia, Chaco. PI SGCYT C12001"Espacio Público en el Gran Resistencia, Proyecto y diseño urbano". Directora: Laura Alcalá. E-mail: ledes.arq@hotmail.com

Palabras Clave: Graffiti - Recurso - Potencial.

Keywords: Graffiti - Resource - Potential

\section{RESUMEN}

El presente trabajo busca trazar un recorrido desde la comprensión peyorativa y común del graffiti, entendido como acto vandálico, hasta su discusión actual en su empleo como recurso en ámbitos tan variados como el artístico, el comercial o hasta el económico, caracterizando y diferenciando modalidades particulares del conflictivo fenómeno, pero que, sin embargo, poseen un provechoso potencial en el ámbito de nuevos sistemas de gestión e intervención urbana.

\section{ABSTRACT}

The present work proposes a timeline which goes from the derogatory depiction of graffiti as an act of vandalism to its current revision and application as a resource by a wide range of fields such as art, commerce and even economics, characterizing and differentiating specific practices of this conflicting phenomenon which have, however, a beneficial potential in the field of urban management and action. 


\section{OBJETIVOS}

Detectar y explorar potencialidades del arte gráfico urbano, que logren recalificarlo como recurso de posible aplicación en mejoras del espacio urbano, cultural y social.

\section{INTRODUCCIÓN}

El presente trabajo es una extensión de la ponencia ofrecida por el autor, con el nombre de "Muros: Imprenta de los Pueblos", en el marco del ciclo de charlas "Ciudad Dibujada" realizadas en la FAU en el año 2011. En el presente escrito debe entenderse el término graffiti como cualquier intervención gráfica, que más allá de sus técnicas particulares, es impuesta en el espacio público urbano, ejerciéndose desde medios no oficiales. En este acercamiento inicial al fenómeno graffiti, se ha propuesto reconocer inicialmente su relevante incidencia en los ámbitos urbanos de todo el mundo, y a partir de esto, su claro conflicto y taxativa concepción peyorativa. Sin embargo, dentro de este suceso tan complejo, es posible cuestionar: ¿la acción gráfica urbana solo puede cumplir la función de degradar el paisaje de la ciudad y de referenciar a fragmentos sociales decadentes? Y de poseer algún tipo de potencialidad, ¿cómo esta puede ser manejada o gestionada para obtener resultados ventajosos?

\section{DESARROLLO}

El graffiti como conflicto

Actualmente, el graffiti es ampliamente considerado como un conflicto o molestia, que a pesar de originarse en grandes metrópolis del mundo, logra afectar a cualquier ciudad, más allá de sus características cualitativas o cuantitativas, donde activos jóvenes (motores de su acción), buscan apropiarse físicamente de las calles con las más diversas actividades, entre las que se encuentra la invasiva gráfica urbana. Gracias a esta, es que para muchos, la acción gráfica no es más que una forma de generar evasivas señales de poca relevancia, que pueden articularse con otras formas de delincuencia, decadencia y marginación en las calles de la ciudad.

Sin embargo, y a pesar de poder servir como medidor de inquietudes sociales, entre todas las actividades calificadas como de "intervención urbana", es el graffiti la única, que a partir de su grado de intervención, es categorizada como un acto vandálico, entendiendo a este como un comportamiento o acto ilegal de marcada hostilidad hacia la propiedad, llegando al deterioro o destrucción de ella. A pesar de esto y debido al tipo de intervención que ejerce, caracterizada por una posible reversibilidad y daño reducido en comparación a otras acciones, el graffiti es comúnmente entendido como vandalismo en menor grado; en este sentido algunos graffiteros, en defensa propia, se refieren a la acción gráfica como "un mal menor", contra el que los gobiernos aman luchar, debido a su relativa facilidad de erradicación momentánea, con claros, fáciles e inmediatos resultados visuales de "mejoramiento del espacio urbano".

El problema, puede ser entendido al amparar los conflictos que se establecen en la relación dada entre la acción graffitera y las características propias del espacio público, como lugar innato de expresión masiva. A partir de esto, se puede observar la intervención de tres actores fundamentales: los realizadores de graffitis contra los organismos de gestión o gobierno y, los vecinos de la ciudad, como entes afectados directamente.

Además de los conflictos respecto del daño físico visible en elementos y espacios del medio urbano, subyacen determinados problemas sociales, culturales, y económicos que el fenómeno graffiti encierra masivamente en la actualidad. Como muestra y respuesta práctica a esta situación, actualmente en el mercado, se presenta la innumerable oferta 
1. Invasiva pintada en modalidad Taging

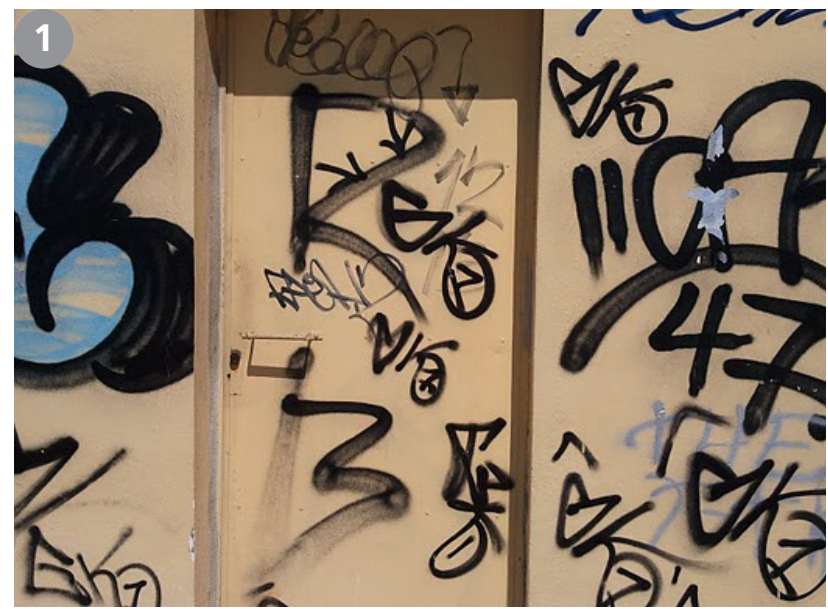

de productos, como pinturas y limpiadores antigraffiti, además de otros recursos de mayores costos, como la generación de situaciones de control o prevención de elementos, por medio de cámaras de vigilancia o excesiva iluminación. Estas ideas son adquiridas por ciudadanos comunes, quienes con intenciones de una mejora estética de su espacio público inmediato, buscan erradicar cualquier irrupción extraoficial de su ámbito.

Sin embargo, los mayores gastos económicos quedan expresados desde la especial atención que otorgan a la lucha en contra del graffiti gestiones gubernamentales. Estas sumas se justifican desde el mantenimiento y recuperación de espacios urbanos, hasta recursos legales y penales, referidos a multas (entre cien dólares y hasta seiscientos euros), ejecución de penas y leyes en relación con el abuso sobre el dominio público y privado. Desde este nivel, son varios los países que al año llevan gastadas sumas que alcanzan los cientos de miles de dólares, encontrándose entre los casos más relevantes Estados Unidos, España, Grecia e Inglaterra, con un promedio de unos dos millones de euros al año en cada gran ciudad de estos. A pesar de estas consideraciones peyorativas sobre el graffiti, y considerando otro tipo de crisis y necesidades actuales y comunes a todo el mundo, el caso en cuestión puede pasar como un conflicto menor en cualquier ámbito urbano. (Fig. 1 y 2).

\section{EL GRAFFITI COMO RECURSO}

Al hablar de un recurso puede entenderse este como algo material o inmaterial, que siendo trasformado o consumido, presenta la posibilidad de proveer algún beneficio, o suplir necesidades, a partir de sus características y potencialidades. La comprensión del fenómeno graffiti como recurso en forma mítica, radica básicamente en ser un hecho esencialmente comunicativo y expresivo. A partir de esto, es que puede entendérselo como
2. Esténcil de Banksy sobre la situación bélica en el Muro de Cisjordania.

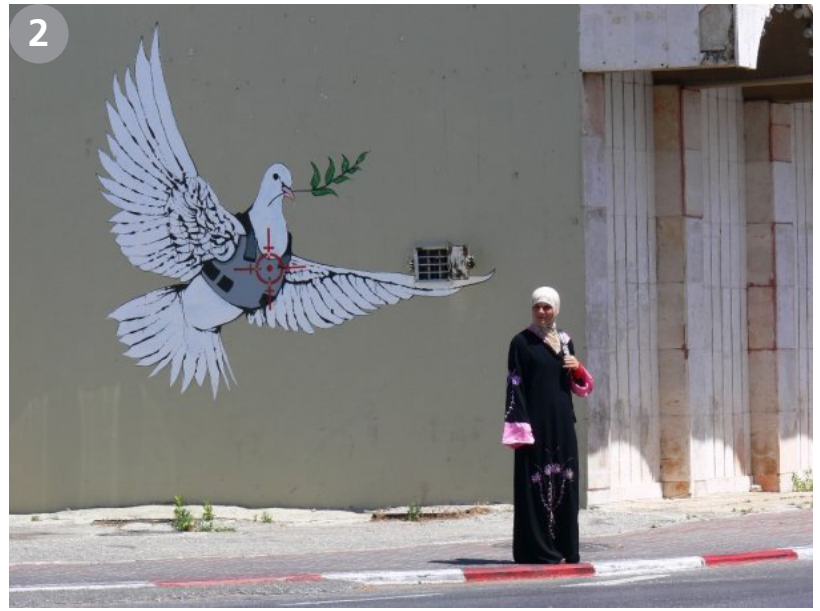

un producto cultural, que además de sus tan variados conflictos, presenta características de alta potencialidad, a nivel de expresión social y cultural. Esto queda explícito en la relevancia que toman las manifestaciones gráficas en el ámbito urbano, como importante medio de exposición, promoción y difusión de ideas, entendiendo a las acciones gráficas como fundamental herramienta en la configuración de escenarios de protesta populares, ejercidos por cualquier habitante, pero especialmente por sectores olvidados o carentes de atención ciudadana.

A partir de buscar la mayor difusión posible de su contenido, el graffiti logra un alto impacto en el medio físico y social; claros puntos de comparación con otro gran fenómeno gráfico, característico del espacio público, como es la publicidad gráfica urbana. Sin embargo, en el primero, los métodos de producción, y los propios recursos de promoción de ideas, son de carácter meramente informal y caseros. De esta forma, esta acción gráfica informal depende plenamente del ingenio y destreza de su autor, referidas no solo al ámbito plástico o temático del contenido, sino también a formas, métodos de ejecución y "marketing urbano" propios de una actividad no lícita. El alto impacto que puede conseguir una acción gráfica no oficial en el paisaje urbano se fundamenta no sólo en el volumen de su acción, sino también en muchos casos en la calidad de sus resultados.

Además de poseer un claro valor comunicativo de los más diversos contenidos, el graffiti logra establecerse como una disciplina, que en el rigor de la palabra y al igual que otras actividades urbanas, llega en casos a tomar distancia considerable de acepciones meramente peyorativas, ligadas a la marginalidad y corrupción. Estas nuevas búsquedas dentro de la acción gráfica urbana se originan de forma natural en la exploración de sus propias potencialidades, con el único fin de obtener productos más elaborados o innovadores, a modo de eminentes expresiones de reconocimiento social, 
3. Obra de arte mural, a base de técnicas graffiti

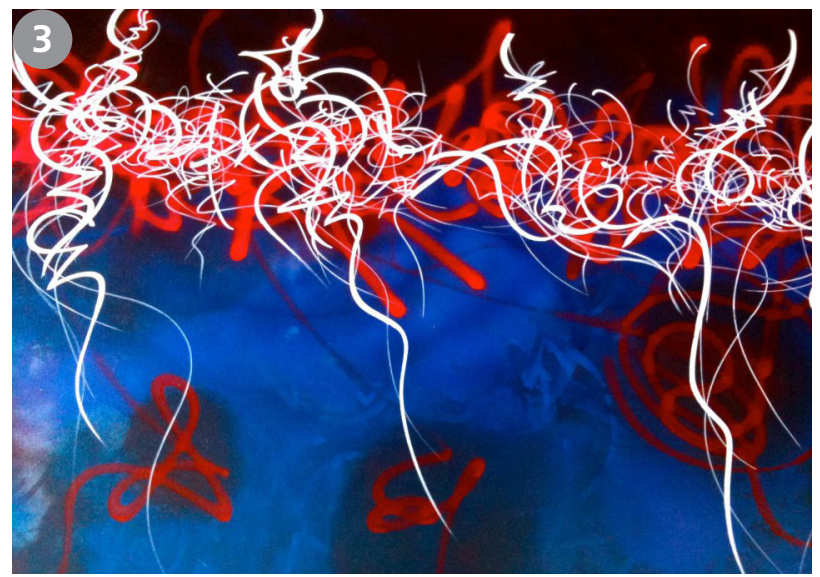

de individuos o grupos, en medios urbanos complejos como fueron los barrios bajos de la ciudad de Nueva York en la década de 1970.

Además de ser, desde su origen, una forma de comunicación y expresión espontánea e informal, caracterizada por un audaz empirismo en sus formas de hacer, es a partir de sus claras potencialidades plásticas, referidas a sus métodos, materiales y técnicas, que logra llamar la atención de disciplinas de carácter académico o institucionalizadas, referidas al ámbito del diseño, estética en general, además del marketing y hasta del arte mismo. Y es a partir de este acercamiento que se obtiene una mejor conceptualización del fenómeno graffiti, logrando tenderse explícitas incidencias entre ellas, con los más innovadores y fértiles resultados en estos campos.

A partir de esta articulación entre conocimientos institucionalizados o académicos, y la experiencia real de un sistema de comunicación más directo, perspicaz y llamativo, propios de la actividad gráfica urbana, es que el graffiti logra enriquecer su producción, desarrollando lo que se conoce comúnmente como "arte gráfico urbano", más allá de las múltiples discusiones sobre la inclusión del graffiti como disciplina artística.

"Graffiti: ¿Arte o vandalismo? ¿Crea o destruye?", es la cita común que cae en la inexactitud de generalizar superficialmente a toda actividad gráfica urbana con el mismo grado de valoración, sin determinar y diferenciar las determinadas destrezas o potencialidades plásticas, expresivas, comunicativas y hasta evocativas de estas según cada caso; además de aferrarlo a la cotidiana idea de vandalismo, sin posibilitar la diferenciación entre modalidades vandálicas o artísticas.

Actualmente es posible entender la particular profesionalización dentro de la actividad graffitera, y cómo a partir de esto, esta termina configurán-
4. Keith Haring a bordo de su característico e intervenido Ford SXX

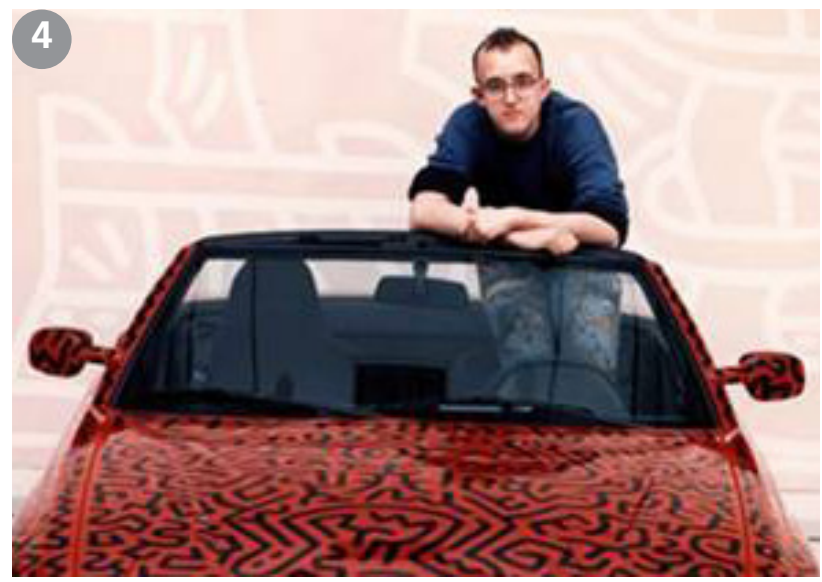

dose en novedosas modalidades legales en la ejecución del arte gráfico urbano. Estas acciones se caracterizan por el permiso de la acción con pleno consentimiento de propietarios sobre los soportes a intervenir (en general muros $u$ otros elementos ubicados directamente en el espacio público urbano); y por una motivación inicial, que lejos de centrarse en la agresión o invasión gráfica, se funda en el desarrollo de piezas de desarrollo plástico, con sus respectivas implicancias y ventajas culturales y sociales. Sin embargo, estos tipos de acciones son duramente criticadas por los activistas más extremos dentro de la contracultura de la gráfica urbana, acusándolas como deformaciones de la propia actividad o como la pérdida de la esencia misma del graffiti.

Esta forma de intervención caracterizada por el consentimiento no es actual, ya que muchos artistas urbanos han accionado activamente, como parte de gestiones oficiales de todo el mundo, en el mejoramiento urbano desde la década de 1970. Sin embargo, se ha generalizado en el último tiempo, en respuesta al envejecimiento de graffiteros, quienes llevaron sus años de "activismo" gráfico, en pleno boom del arte urbano (1970 y 1980), y hoy cuentan con una edad mayor a los cuarenta años. A partir de esta situación es que muchos abandonan las "corridas callejeras" para buscar la tranquilidad legal frente al muro, la que permite la inspiración y fluidez de una cargada creatividad, como cualquier otro artista maduro. (Fig.3 y 4).

En relación con la imagen del artista y el graffiti, no puede dejar de nombrarse al joven Keith Haring, quien en una consumista búsqueda pop, se apropia y descontextualiza las coloridas expresiones gráficas de los barrios bajos de la ciudad de Nueva York, utilizándolas como inspiración estética a partir de las cuales elabora un estilo propio. Haring no es el primero, pero sí uno de los más efi- 
5. "I Hate Mondays". Satírico acrílico sobre tela de Banksy, subastado por Sodeby’s en 70000 dólares.

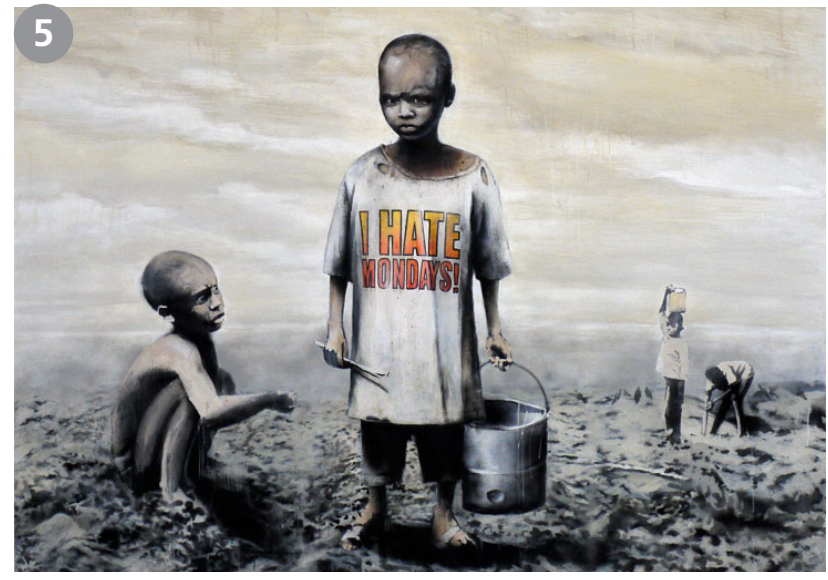

caces precursores en el proceso de popularización e introducción de la llamada "estética urbana" en el ámbito artístico oficial, además de extenderla también a la industria del comercio banal, aplicándola en los más variados objetos cotidianos.

Actualmente el caso extremo, en el ámbito comercial, se centra en torno a la reconocida figura del graffitero inglés Banksy, quien se caracteriza por un fuerte activismo y anonimato, además de ejercer, una dura crítica a la idea de arte como mercancía para unos pocos y también sobre la cuestión del street art como expresión de gran valor artístico. A pesar de ello, las relaciones de este con el comercio del arte son constantes, logrando, en contradicción a sus propias críticas, realizar exposiciones y fastuosas subastas de obras de galería, que a pesar de poseer su satírico estilo, se presentan en formatos y soportes plenamente adquiribles, como cualquier otra obra de arte. (Fig. 5 y 6).

A partir de lo dicho puede comenzar a entenderse cómo las relaciones del graffiti con el campo del arte han sido productivas en ambos sentidos, y cómo este también ha logrando configurarse en un recurso artístico en ámbitos oficiales.

Más allá de que en la historia de la humanidad se haya presentado la intervención plástica sobre los paramentos o muros, como una modalidad común con los más diversos fines de promoción de ideas, o simple desmaterialización del elemento soporte con base en expresiones artísticas, es hacia las búsquedas contemporáneas de la segunda mitad del siglo $X X$ que el graffiti ha logrado penetrar en ámbitos académicos como nueva pero conocida y "urbana" forma de expresión.

Sin embargo esta visión esteticista corre el riesgo de ser distante y colonialista frente al "suceso graffiti", considerando a estas expresiones gráficas como mera mercancía de llamativa estética
6. Pieza de arte graffiti con claras influencias artísticas.

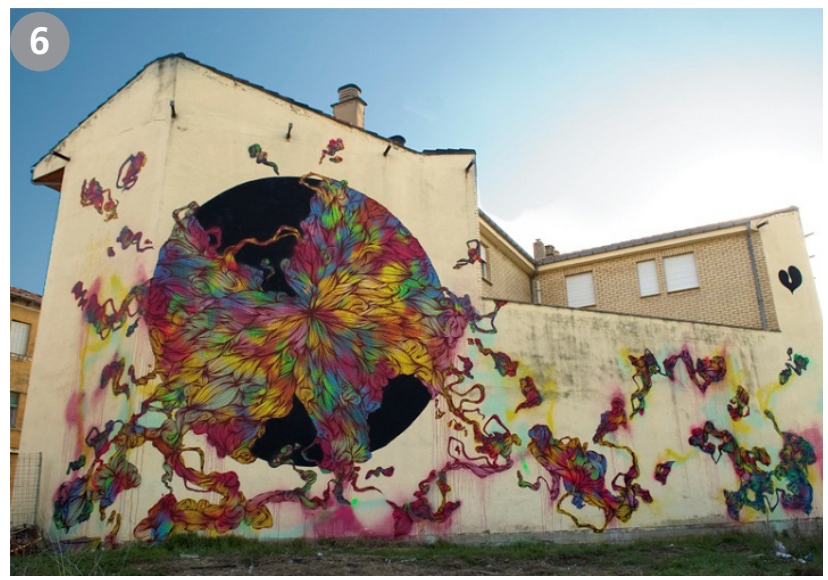

exacerbadamente formal y colorida, a las que solo la industria y el comercio han sabido darle un espectacular provecho en la toma de imágenes referenciales de un expresión novedosamente "callejera o urbana". El graffiti forma parte esencial del imaginario de lo que comúnmente se denomina "cultura urbana", y es a partir de la toma de esta como concepto comercial que desde marcas de indumentaria hasta grupos musicales o bebidas se han apropiado de la imagen de las expresiones gráficas urbanas, entre otras actividades, a forma de referencias o recursos publicitarios.

\section{GESTIÓN DE MUROS: EL GRAFFITI COMO POTENCIALIDAD URBANA}

Además de sus particularidades míticas, como ser un medio de expresión directa, accesible y popular de inquietudes y reclamos por parte de la población, actualmente son muchas las ciudades de todo el mundo que ejercen la lucha contra la cara vandálica del graffiti. Pero son otras tantas de las que han logrado generar particulares situaciones y espacios determinados para lograr cobijarlo y darle provecho en su propio medio físico y social, tomándolo como innovador recurso activo, de características potenciales para el mejoramiento de las diversas dimensiones del espacio público y el medio urbano en general. Innumerables son los casos en los que a partir de una actividad graffitera controlada se logra por medio de diversas gestiones la recuperación de espacios puntuales de la ciudad. Ejemplos de esto se presentan en los actuales encuentros de graffiti en los que se articulan diversas actividades y deportes "urbanos".

Estos eventos son organizados por los mismos organismos públicos o privados, que logran convenios con la ciudad, gestionando la sesión de espacios, muros o edificios en decadencia, que buscan 
7. Intervención artística en ex poblado minero en el interior de Perú.
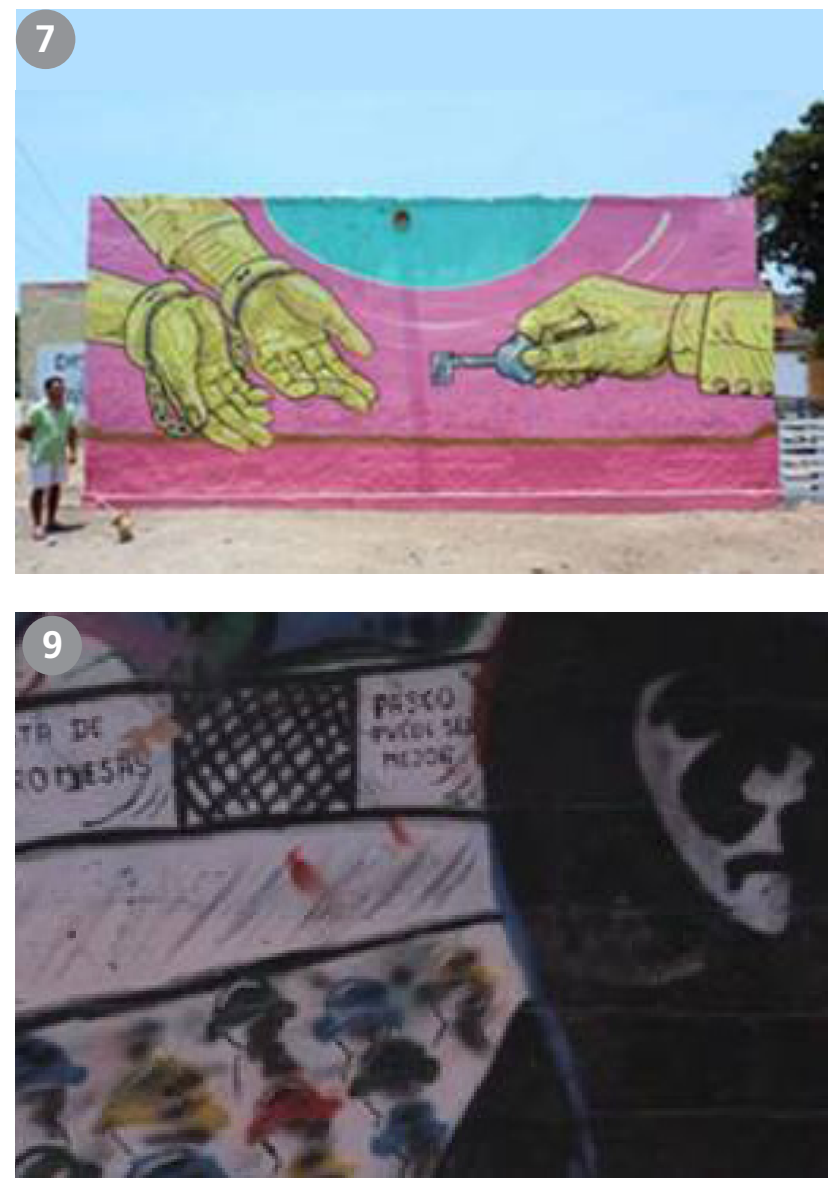

ser mejorados estéticamente.

A partir de esta acción de ceder espacios degradados para ser intervenidos de forma controlada es que se logran desarrollar nuevas formas de enfrentar al graffiti, ya no rechazándolo y luchando contra él, sino amparándolo y controlándolo. Este modelo de "gestión del graffiti" centra su atención en las potencialidades propias de la actividad, lque lo moldean y orientan, para tornar la intervención en una ventaja empleada en el mejoramiento y recuperación urbana.

Claro está que estos modelos de gestión centran su atención principalmente sobre las acciones gráficas de gran elaboración plástica, logrando de esta forma, inicialmente, una mejora del paisaje urbano. Sin embargo, muchas de las ciudades poseen importantes problemas con los tipos de actividad gráfica que, además de servir como datos a estudios científicos, no presentan grados de desarrollo estético que puedan ser explotados a simple vista. Con esto debe entenderse que no todas las acciones gráficas urbanas son susceptibles, por lo menos por vías simples, de potencializarse y aprovecharse como motores de mejoras.

Caso particular en Latinoamérica es el llamado Proyecto Afuera, un encuentro de arte urbano en Perú, que cuenta con la participación de artistas
8. Protesta gráfica en Cerrodel Pasco, decadenteciudad minera. 9. Muro de Berlín, Alemania (lado Occidental) como muestra de uno de los más prolíferos museos al aire libre, referidos no tanto al artesino a la historia particular de un puebloyel mundo.
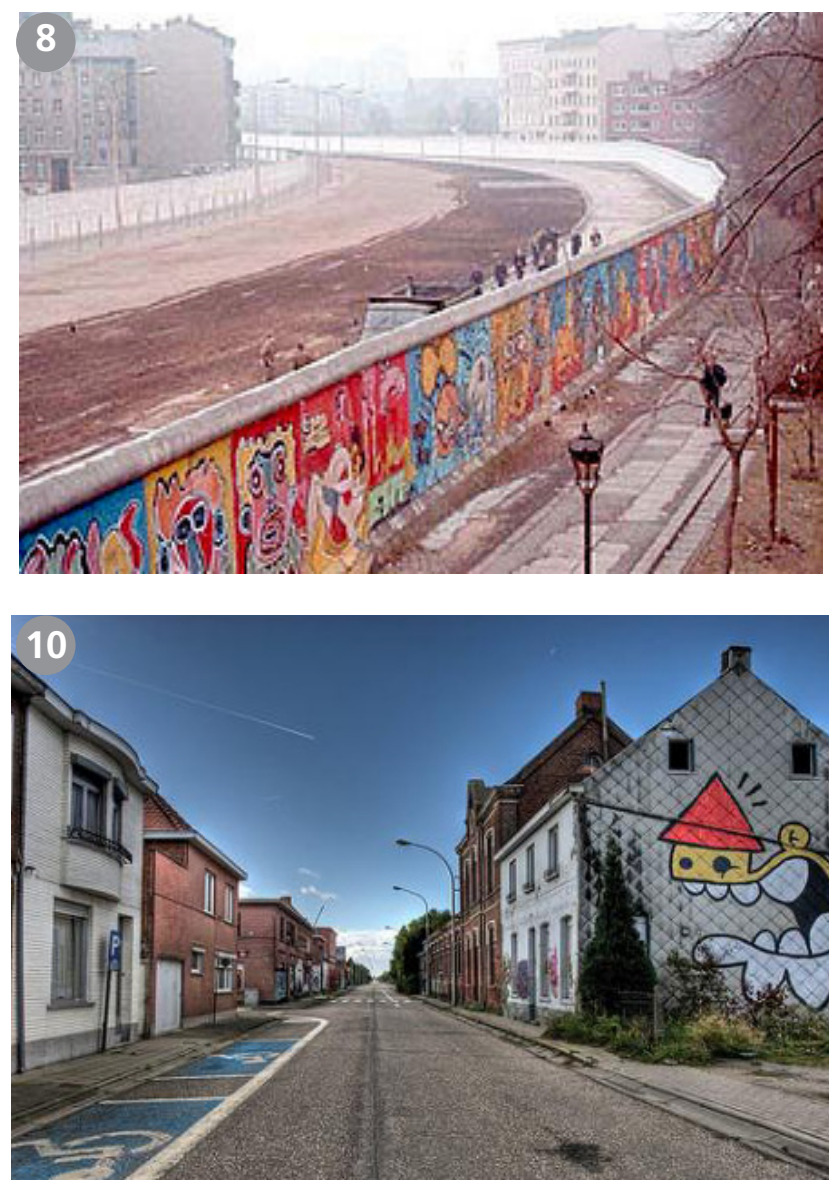

nacionales e internacionales, con la finalidad de pintar murales en los lugares más recónditos de ese país, que normalmente están fuera del foco del arte, en búsqueda de sensibilizar y lograr un impacto positivo en dichas comunidades. (Fig. 7 y 8).

Asimismo se espera la integración de los artistas participantes a un entorno ajeno al suyo, los que confrontarán con experiencias que nutrirán sus procesos creativos, y generarán un diálogo y reflexión entre ellos, la población y el entorno cultural de la ciudad. La actividad del encuentro se centra en temas sociales de la zona y enfatiza su acción en los espacios de centros mineros e industriales olvidados, buscando, además de aprovechar sus extensas superficies, liberar a estos centros urbanos de su marcada decadencia.

Además de las intervenciones con fines de recuperación o mejora estética, son innumerable los casos en el que el graffiti convierte a la calle en un verdadero "museo a cielo a abierto", relacionándose plenamente en esta concepción la idea de acción gráfica como arte, ciudad y recorrido, pero que fundamentalmente puede implicar su aprovechamiento económico como recurso de atractivo turístico. Es así que muchas ciudades, principalmente europeas, buscan actualmente ser intervenidas por 
10. Graffiti en medio de la desolada ciudad belga de Doel.
11. Recorridos guiados por los graffitis del barrio de Palermo y obras adquiribles en la galería desde $\$ 50$ hasta $\$ 4000$.
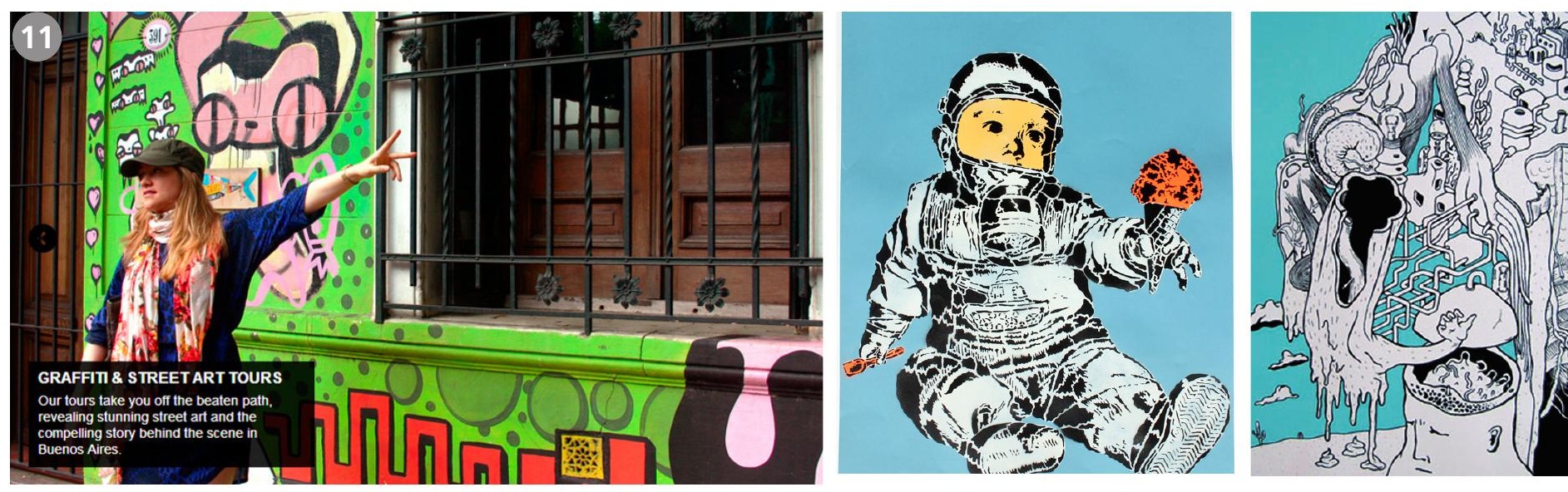

renombrados artistas del arte callejero y así lograr convertirse estratégicamente en puntos de peregrinaje de un flujo turístico joven, quienes además del consumo gratuito de imagen urbana, logran el consumo de otros tantos productos y servicios. (Fig. 9 y 10).

En relación con el aprovechamiento como recurso turístico, además de los numerosos casos de ciudades españolas, puede citarse el de la olvidada ciudad belga de Doel, reducido poblado portuario que debido a problemas de gestión regional, ha resultado literalmente deshabitado en el año 2000. A partir de esta situación de pueblo fantasma es que cientos de artistas urbanos logran tomarlo como soñado patio de juego, interviniendo en sus muros con las más variadas piezas de un graffiti que, indiscutiblemente, puede ser llamado arte.

En referencia al ámbito argentino, si bien pueden identificarse numerosas acciones gráficas, no constituyen actualmente un problema relevante. Sin embargo, son sus grandes centros urbanos los que demuestran mayor presencia del graffiti de elaboración plástica o de lo entendido como "arte gráfico urbano". Y es a partir de ello que ciudades como Buenos Aires poseen ofertas turísticas en relación con la existencia de estas acciones gráficas, que a pesar de ser característicamente extraoficiales a ámbitos académicos, presentan elevadísimo valor estético y económico. (Fig. 11, 12 y 13).

A partir de esto se organizan emprendimientos privados, que centran su actividad en recorridos gratuitos, en los que curadores y entendidos en arte enseñan y explican las grandes piezas del graffiti en barrios céntricos de la capital argentina. Como complemento al circuito, este finaliza en la sede y galería de muestra, donde los mismos artistas urbanos logran exponer piezas, que a pesar de conservar su estética propiamente urbana, se presentan en formatos plenamente adquiribles. (http://graffitimundo.com/).

\section{CASO BONAERENSE}

El caso local de mayor relevancia en cuanto a la lucha contra el graffiti es, tal vez, el ejercido por la actual gestión de Mauricio Macri en la ciudad de Buenos Aires, debido no solo a las críticas laterales de ciudadanos sobre las particulares acciones sobre el problema, sino también la instrumentación física o social sobre el conflicto.

Inicialmente debe considerarse que la ciudad de Buenos Aires es una de las más extensas e importantes metrópolis de Latinoamérica, a partir de lo que puede entenderse la presencia de una efervescente cultura urbana joven, de tendencia global, compuesta de todo tipo de actividades y modalidades de uso, en ocasiones conflictivas, en el espacio público. Dentro de estas actividades, no solo puede citarse a patinadores, skater y bykers, también acompañan otras modalidades centradas en grupos y modas, las que a partir de diversos medios, logran marcar su existencia y apropiación dentro de los espacios públicos de la ciudad, y configurarse como potentes subculturas dentro del medio urbano. Hace ya unos años que la acción graffitera logra imponerse ferozmente sobre el espacio urbano bonaerense, consiguiendo la apropiación gráfica no solo de espacios definidos con las actividades relacionadas de la subcultura urbana, sino que desborda y ataca indiferentemente a todo elemento disponible al paso, en el espacio público.

Actualmente, recorriendo el centro de Capital Federal, pueden ser halladas grandes piezas gráficas de importante elaboración plástica, emplazadas en lugares de usos específicos, como pistas de skate o lugares de común encuentro para estos grupos. Pero el resto de la ciudad también se ve excesivamente intervenido, particularmente por la llamada modalidad gráfica del tag. Este grafismo urbano, originado en los años 70 en los Estados Unidos, que luego se expandió a todo el mundo, se 
14. Publicidad política que plantea las" evidentes" mejoras a partir de las intervenciones de la gestión.

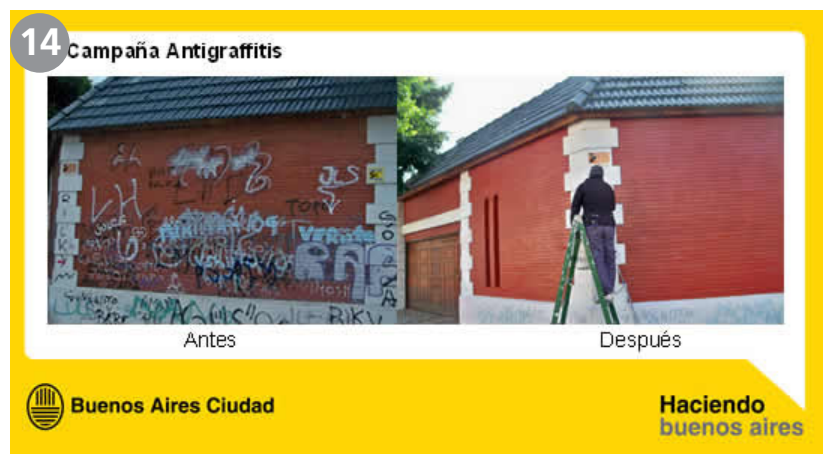

caracteriza por una acción de escritura fundamentalmente rápida, con escueto contenido, que en general referencia nombres de individuos o grupos, a partir de tipografías poco legibles, producto de una característica agilidad en su ejecución con rotuladores u otro tipo de marcador.

Es justamente en la acepción del llamado bombing (término anglosajón traducible como bombardeo que define la actividad del tag, generalmente vandálica, de circular e intervenir las calles con invasivos y veloces grafismos, sean firmas o graffitis), quedando definida la idea de "destrucción" del espacio a partir de ser intervenido: "El Bombing, es análogo a los tiradores de bombas o granadas en combate, ellos al igual que nosotros buscan la destrucción para ejercer la lucha contra determinados enemigos" (Joven neoyorquino, 1977). (Fig. 14 y 15).

De esta forma puede comenzar a establecerse la importante presencia de intervenciones gráficas puntuarles de posible valor plástico o valorativo, pero también de otras, de carácter más perjudicial al presentarse como meros "rayones" en el paisaje urbano, en relación peligrosa con la idea de cualquier joven que circule por la ciudad.

Es a partir de esta situación degradada del paisaje urbano que la gestión de Mauricio Macri busca atacar el fenómeno del grafismo urbano no oficial, con el fin de "limpiar la ciudad": "Con el objetivo de reparar y limpiar las fachadas afectadas por los graffitis en todas las Comunas de la Ciudad, la Secretaría de Gestión Comunal y Atención Ciudadana continuará durante este año con la campaña antigraffiti y antipegatina iniciada a fines de 2010." (www.gobiernodelaciudad.com).

Sin embargo, y como es común en toda acción política, un numeroso sector de vecinos manifiestan desacuerdo respecto de la acción de ocuparse del graffiti de la ciudad, acusando a Mauricio Macri de sostener un modelo de gestión político meramente
15. Intervenciones gráficas sobre publicidad macrista, que además de plantear el valor comunicativo, demuestra la capacidad de diálogo ejercida sobre las superficies de la ciudad.

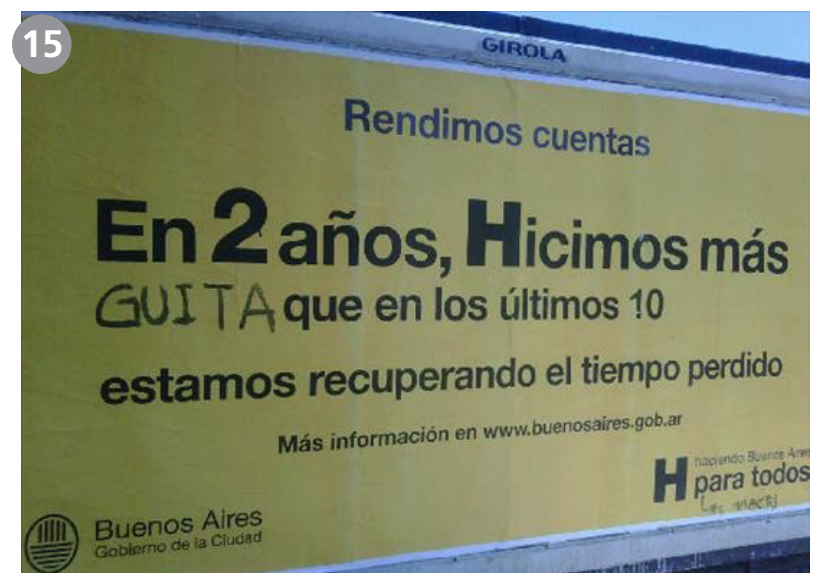

visual, con fuerte tendencia publicitaria, refiriéndose ellos a cualquier acción que logre alto impacto expansivo y visualmente evidente dentro de la ciudad. Otro de los puntos en cuestión, como lo explica Claudia Kozak, son las patentes contradicciones establecidas a partir de la típica invasión de gráfica publicitaria en épocas electorales, además de contradicciones implícitas en estas, en referencia a la imagen del ciudadano graffitero. Fig. 16

Además de extensas y llamativas campañas de difusión, la "acción de limpieza urbana" fue llevada a cabo a partir de organizar las llamadas "unidades antigraffiti": transportes móviles, que con las identificaciones gráficas características y equipa con instrumentos para ejecutar la limpieza gráfica de las calles, realizan recorridos por temporadas en los diferentes barrios de la ciudad.

Otra de las piezas fundamentales en esta gestión sobre los muros de la ciudad es la realizada por grupos de apoyo, como el de "Los Jóvenes $P R O$ ", Ios que a partir de adherirse al frente político macrista, Ilevan a cabo, entre otras acciones, la "limpieza gráfica de la ciudad". Sin embargo, lo realmente valorable de una visión joven en relación con el tema radica en su particular capacidad de ejercer una real diferenciación de calidades de expresiones plásticas o valorativas dentro del arte gráfico no oficial, y de poder entender su potencialidad en relación con la ciudad.

A partir de esto, el marco de acción queda inicialmente definido por la exigencia de limpiar toda intervención gráfica ejercida perjudicialmente sobre elementos del espacio público, o que deteriore edificaciones u objetos de valor patrimonial. En segundo lugar, se presenta la posibilidad de salvar y destacar la presencia de determinadas piezas gráficas, a partir de ser portadoras de algún tipo de valor o potencialidad reconocido y evidente, generalmente en relación con el contenido y des- 


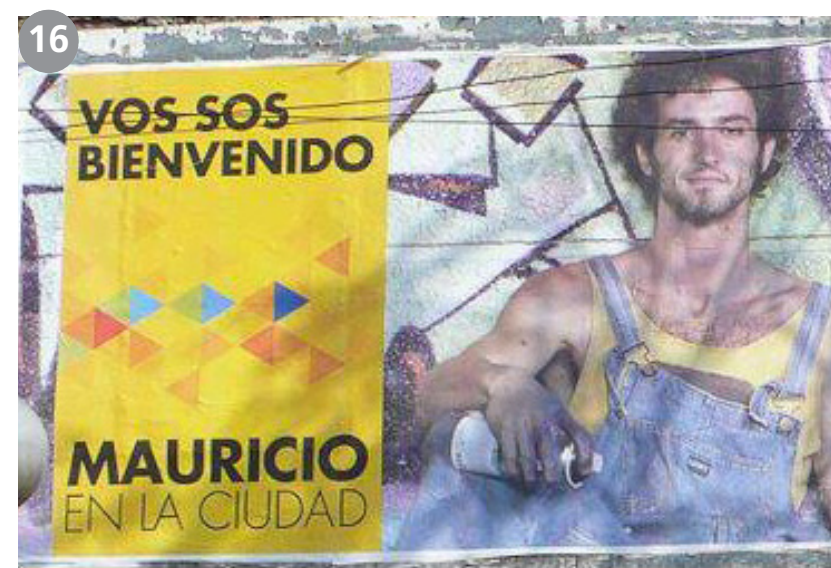

treza plástica de esta, sin embargo esta segunda, por ningún motivo puede transgredir a la primera.

"Los Jóvenes PRO Capital comenzamos con una campaña de restauración de fachadas, para limpiar y poner en valor cualquier espacio que se encuentre pintado de manera no artística y que contamina visualmente la Ciudad de Buenos Aires." (www.gobiernodelaciudad.com).

Es desde estas reducidas pero innovadoras visiones, alternas a las acciones comunes, puede comenzar a entenderse que a partir de detectar potencialidades plásticas, sociales y culturales, se inicia la promoción de actividades a favor de la acción gráfica urbana, entendida como medio de comunicación y expresión artística valorable para la mejora del espacio público.

Es desde este panorama, y a modo de ilustración, que resulta inevitable recordar y poner en paralelo el curioso cuento de 1981 del escritor argentino Julio Cortázar, titulado "Graffiti". En él, los muros y gráficas se expresan de forma mítica como especial medio de comunicación entre individuos que se buscan en la ciudad, en plena situación de represión (representada por "camiones de limpieza"), pero también quedan establecidas la habitual respuesta y las discusiones ejercidas gráficamente sobre estos símbolos y situaciones que representan la prohibición y control ejercidos por el poder oficial.

\section{GESTIÓN DE GRAFFITI: EL CASO ESPAÑOL}

España es uno de los países que más afectado se ve actualmente por el graffiti, por haber sido uno de los principales focos de atracción, a inicios de la década de 1980, en la expansión de la particular modalidad gráfica proveniente de América del Norte. A pesar de esto, España ha podido sobrellevar este conflicto por diversos medios y acciones durante mucho tiempo, alcanzando reconocimiento por la calidad y control de estas intervenciones

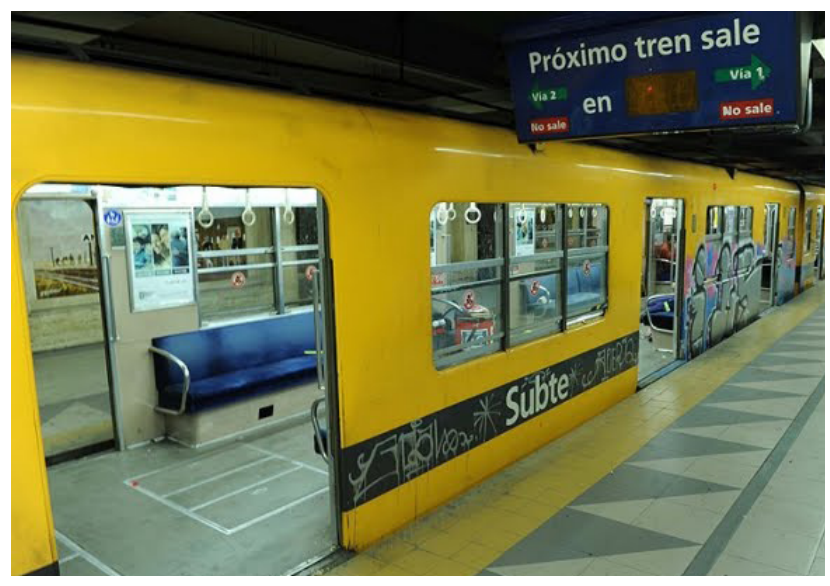

sobre su paisaje urbano.

Una acción inicial en esta lucha consistió en la redacción de su famosa Ley Antigraffiti, que en su momento fue una innovación a nivel mundial, sirviendo como modelo a las normas de otros tantos lugares que buscan enfrentar a la acción gráfica urbana, como el caso de la Provincia de Entre Ríos en Argentina. Esta ley ataca la acción, fundamentalmente desde la restricción y control de elementos, prohibiendo la venta de aerosoles a menores de 21 años: "Los comercios tendrán que llevar un registro de los aerosoles que vendan y a quien se lo vendan (nombre, DNI, dirección y demás datos personales); en caso de venderle pintura a los menores de edad que no tengan el permiso de los padres, serán multado los comerciantes, y si el menor comete alguna 'injuria', o acto vandálico como pintar fachadas o monumentos históricos, se multará a los padres con la suma que requiera el 'arreglo' de dicha pintada".

Sin embargo, al tiempo de establecida la Ley en España, se observaron ciertas fallas propias de un sistema que buscaba proscribir peligrosamente una situación tan particularmente activa y reactiva a nivel cultural como son las expresiones urbanas en territorio español. Esta situación se debe a la particular apertura que presenta la península a la recepción de la cultura urbana Hip-Hop neoyorquina, con la que no solo se importan tendencias de la cultura popular (moda, música, baile y estéticas en general), sino también actividades y formas de vida específicas, que terminan configurando imaginarios sociales y culturales, sobre la idea de lo llamado comúnmente "cultura urbana".

A partir de esta nueva tendencia, particularmente reactiva, considerada como contracultura, es que muchos jóvenes, algunos por moda, otros por sentirse identificados por su situación de marginalidad y decadencia, comienzan a modelar su espacio social, desde esta nueva tendencia. De esta forma es que logra expandirse un graffiti de carácter de- 
17. Intervenciones del arte gráfico en la ciudad española de El Crucero (León).

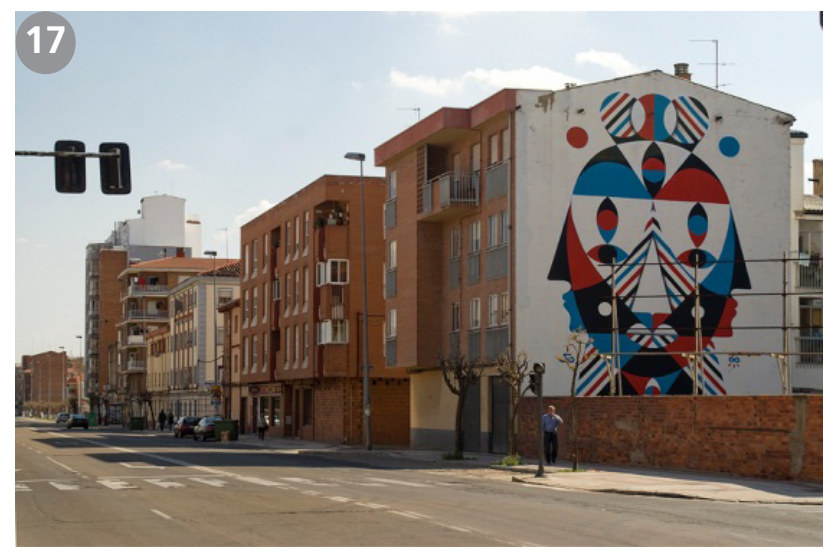

lictivo, desarrollado generalmente por grupos de jóvenes ligados al mal vivir, pero que todavía en su mayoría cuentan con un altísimo valor estético y comunicativo, además de ser un nuevo tipo de expresión en el medio. Esta situación es la que concluye hoy en día, ya sin mucho contenido o razón de ser en algunos casos, más que del mero perjuicio a fin del entretenimiento a cargo de agresivas bandas adolescentes, que no ejercen otra acción más que la simple mancha o rayado del espacio urbano. (Fig. 17 y 18).

Lo particular del caso español es que estas acciones toman importante relevancia también fuera de los grandes centros urbanos, situándose en pequeños poblados, donde el daño es más evidente $y$, en consecuencia, la lucha es más directa. Pero lo realmente grave es que el graffiti es solamente la expresión gráfica de una agresiva contracultura adolescente, que llega a incurrir en ámbitos del delito, que deja muy por detrás a los orígenes de los suburbios neoyorquinos. En respuesta a este panorama, los vecinos y el gobierno de ciudades españolas, ya hace décadas, han reaccionado duramente, aumentando la vigilancia y el control, y penalizando seriamente (multas de hasta 900 euros), por daños ejercidos sobre la propiedad pública y privada. En todos los casos, los mayores daños no están referidos a reconocidos referentes o grupos de artistas urbanos, sino a simples miembros jóvenes de la comunidad de reconocimiento intrascendente, principalmente amateurs en la acción. Sin embargo, existen casos de luchas puntuales contra el graffiti, como la ejercida contra el inglés Banksy, quien a pesar de ser reconocido y venerado por el mundo entero como hito del graffiti, es a la vez catalogado por el Gobierno de la Corona como enemigo público. Es a partir de este contexto los gobiernos y ciudadanos buscan falsas soluciones ideales, basadas solamente en el control y represión de la actividad graffitera, obteniendo como resultado, de estas imposiciones, una mayor agresividad y acción por parte de sus activistas gráficos. En este punto, debe entenderse que el fenómeno
18. Intervenciones del arte gráfico en la ciudad española de El Crucero (León).

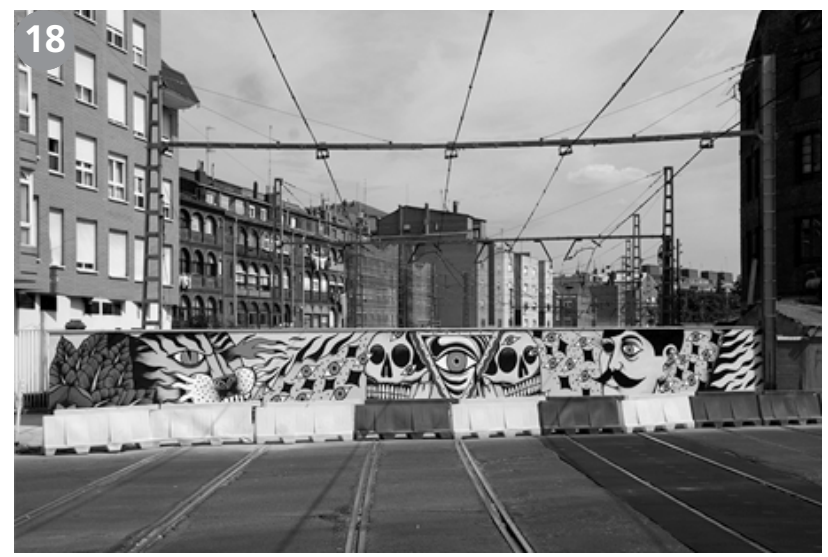

graffiti, en general, presenta una delicada variabilidad sobre situaciones de comportamiento más o menos caprichoso y reactivo, que requieren un complejo control, a lo que se suma la falla de un sistema que busca imponerse sobre este. Estas fallas en la búsqueda de situar límites y lograr controles, en el caso de las expresiones gráficas urbanas, tienen actualmente resultados efectivos, a partir de entender al problema desde la leyenda popular: "Si no puede contra ellos, úneteles". De esta forma es que, desde los gobiernos y municipios españoles, así como desde los mismos barrios, se expresan nuevas actitudes de inclusión que logran abordar de forma integral parte de las problemáticas de las gráficas urbanas. Este modelo de gestión Inclusivo se caracteriza por lograr y fortalecer otra calidad de valores en su acción, a partir de una serie de recursos e instrumentos novedosos. Estos modelos de "gestión del graffiti" buscan entender la magnitud del problema urbano de la acción grafica no oficial, y tienen como actores principales a reactivos jóvenes, que toman las calles como espacio liberado para la expresión, sin importar la propiedad pública ni privada, ni tampoco los demás usuarios de aquel. A partir de esto, se buscan acercamientos extremos con las acciones y manifestaciones de las expresiones gráficas, al proponer amistosamente ámbitos y espacios para su desarrollo controlado.

Es así que en numerosos municipios, las mismas intendencias son las promotoras de encuentros de arte callejero y otras expresiones, no solo con fines de lograr un mejoramiento estético del paisaje urbano, sino también la inclusión y estratégica regulación de estas actividades desde ámbitos oficiales. Además de las acciones de recuperación y mejora en la imagen urbana, a partir de la intervención de sujetos especializados en el arte urbano, foráneos o propios del lugar, este modelo de gestión también busca la mayor inclusión posible, logrando amparar a una amplia variedad de jóvenes graffiteros inexpertos. Esto es posible a partir de proponer piezas fundamentales en este sistema, 
como son las variadas escuelas de graffiti que, organizadas de manera oficial, imparten no solo conocimientos prácticos sobre la ejecución del graffiti a amateurs, sino que también logran educar cívicamente sobre su correcto empleo. En la realidad práctica, la cuestión transita por el siguiente camino: si un joven quiere, al igual que los artistas urbanos, lograr intervenir los muros de su ciudad, debe acudir y pasar por determinados mecanismos de un sistema que busca explícitamente explotar las potencialidades del graffiti, al mismo tiempo que regular su actividad.

Lo particular de este sistema es cómo en su aplicación logra el acercamiento de toda la comunidad, entendida como vecinos, gobiernos y artistas urbanos, para acordar y posibilitar la intervención. Por otro lado, no solo se cuenta con la recuperación del espacio físico, sino también del espacio social, con recursos fina y estratégicamente centrados en la mejora de los individuos jóvenes. Sintéticamente el núcleo del modelo de gestión se centra en atacar al problema desde su raíz real, la que se relaciona directamente con la formación del conocimiento, formal o informal, de los mismos agentes productores de graffiti, generalmente jóvenes. En este sistema, estos individuos se ven asociados a atractivos medios que buscan vincularlos con actividades productivas, con el fin inicial de apartarlos de ámbitos perjudiciales.

Como fin ideal, se busca que los jóvenes accedan a intervenir la ciudad, de forma consciente y óptima; y a partir de esto, obtener el reconocimiento de su buena acción por parte de toda su comunidad. También se sostiene la idea de generar una apropiación valorativa y racional del espacio, desarroIlando un fuerte sentido de pertenencia sobre este ámbito. De esta forma es que se busca construir el camino certero hacia un modelo de autoproducción, mejoras y mantenimiento sustentables, basado en un ataque de la dimensión social, que logre repercusiones y devoluciones positivas en el espacio físico urbano.

\section{REFLEXIONES FINALES}

- Inicialmente puede decirse que a pesar de no ser uno de los conflictos fundamentales de las ciudades actuales, el graffiti logra generar grandes inversiones y un importante flujo económico, tanto en su lucha como en su gestión, explicitándose de esta manera el peso del suceso de las expresiones gráficas no oficiales en el medio urbano mundial. - Puede llegar a entenderse al graffiti como producto propio de la forma de vida de la ciudad moderna; considerándolo como medio innato con modalidades de expresión y comunicación de carácter típicamente urbano.

- Más allá de sus desventajas y dificultad de manejo y gestión, la acción gráfica urbana puede ser aprovechada como potenciadora de actividades productivas, recuperadoras y valorativas dentro del espacio urbano, entendiendo a este como su medio propio.

- Para el desarrollo de su gestión, debe estudiarse previamente el caso particular que se va a tratar, ya que el fenómeno graffiti, a partir de caracterizarse por una gran libertad y reactividad, presenta un comportamiento caprichoso, propio de sus fundamentales agentes, los jóvenes, variable en cada contexto.

- A pesar de los inconvenientes de cada situación particular, las acciones gráficas están presentes en todas las ciudades en las que se hallen individuos activos y dispuestos a realizar intervenciones en el medio urbano, las cuales deben ser correctamente aprovechadas y controladas como recurso potencial para el entorno.

- Como acercamiento a la gestión urbana, en relación al graffiti puede entenderse la necesidad de fuertes y claras políticas, no solo de acción sobre el espacio, sino también con respecto a la educación y formación específica de los individuos como ciudadanos realmente comprometidos. 
Ezequiel Ledesma

\section{BIBLIOGRAFÍA}

- Alvoreda Alvarado, Sergio Alejandro (2010) "Grafica popular urbana". http://semillerodg.files.wordpress.com. Boyacá.

- Busquets, Inés (2011) "Las Paredes son la Imprenta de los Pueblos". http://www.pagina12.com.ar. Buenos Aires.

- Figueroa Saavedra, Fernando (1999) "Graphitfragen. Una mirada reflexiva sobre el Graffiti" www.graphitfragen.com. Madrid.

- Kozak, Claudia (2009) "Grafitis y política: apuntes sobre intervenciones y espacio público". http://www.escritosenlacalle.com. Buenos Aires.

- Kozak, Claudia (2010) "No me resigno a ser pared: Graffitis y pintadas en la ciudad artefacto" www.revista-artefacto.com.ar. La Plata. 